\title{
Parallel corpora. A real-time approach to the study of language change in progress
}

\author{
Christian Mair* \\ English Department, "Albert Ludwig" University of Freiburg, Rempartstr. 15, DE-79098 Freiburg, Germany
}

\begin{abstract}
Article info
History:

Received June 3, 2014

Accepted June 12, 2014

Published January 13, 2015

Key words:

corpus linguistics

language change

contemporary English

parallel corpora

informality

Abstract

The paper draws data from four matching one-million word corpora, namely Brown (US, 1961), LOB (GB, 1961), Frown (US, 1992) and FLOB (GB, 1991), in order to provide an integrated description of synchronic (regional and stylistic) variation and short-term diachronic change in written Standard English. The analysis of a fairly large number of morphosyntactic variables shows that instances of direct structural change are rather rare in the period under review. Nevertheless there are numerous statistically significant diachronic developments which, taken together, provide evidence for a coherent discourse-pragmatic trend, the 'colloquialisation' of the norms of written English. This linguistic development is argued to be driven by a more general sociocultural trend, the shift of public taste towards greater informality.
\end{abstract}

\section{Introduction}

The degree of public interest in (and the amount of writing on) linguistic change taking place in presentday English is in inverse proportion to the reliability of the methods chiefly used to study the phenomenon, namely anecdotal commentary by observers, travellers or returning expatriates. This is in stark contrast to research on Old and Middle English, which is inevitably based on the more or less systematic analysis of some part of the extant corpus of written texts. The present paper reports on an attempt to adapt the corpus-based methods used widely in the study of earlier stages of English to research on current changes. In this undertaking, I share the qualified optimism of Janet Holmes, who has argued that:

"The prospect of using corpus data to infer language change over time is an exciting one. It is clearly possible to make suggestive and interesting comparisons between the frequencies of items in corpora of similar size and composition which have been constructed at different points in time. (Holmes, 1994, p. 37).

The 'classic' case of the type of investigation envisaged is the linguistic comparison of corresponding sections of text in subsequent translations of the Bible. The Biblical corpus has remained constant in size and composition, so that the presence of new forms or shifts in the distribution of variant forms are either due to chance or a direct reflection of linguistic change and innovation. Jespersen offers one of many examples of the procedure in question:

The extent to which the language has changed in this respect may be gauged by the comparison which I once asked one of my pupils to make between the Gospel of St. Mark in the AV and in the Twentieth Century Version: while 28 cases of expanded tenses were common to both, the latter had 78 expanded tenses, where the AV had simple tenses, while there was only one case in which the AV had an expanded and the new version a simple tense. (Jespersen, 1909-1949, IV, p. 177).

*Email address: christian.mair@anglistik.uni-freiburg.de. 
Translations of the same text produced at various times are a rare and fortunate case of matching corpora. Projects such as ARCHER (a representative corpus of historical English registers, see Biber et al., 1994) and the Helsinki-Corpus show that results are possible even if the match is defined more loosely-for example the presence of a comparable mass of text instantiating the same or similar text types.

Corpus-linguistic research on modem English was crucially promoted in the early nineteen-sixties by the Brown and LOB corpora - two matching samples of the American and British written standards. These databases have now aged considerably. To preserve their continuing usefulness it was decided to compile replicas - provisionally known as Frown and FLOB ${ }^{1}$ - matching the originals closely in size and composition, but with textual material published in 1992 and 1991 respectively, and not in 1961, as in the originals.

The set of four matching corpora thus available was expected to make it possible to:

i. test at least some current hypotheses on linguistic change in present-day English;

ii. detect changes not previously noticed in the literature through the systematic comparison of lexical frequencies, particularly of closed-class items;

iii. tackle systematically one of the major methodological issues in the study of ongoing change, namely the inter-dependence of synchronic regional (in our case British vs. American) and stylistic variation on the one hand, and genuine diachronic developments on the other.

A word is probably in order here on what the corpora cannot be used for. They will not serve the user to home in on the origin of an innovation. Most phonetic and morphosyntactic changes probably originate in speech and then spread into writing, and even when dealing with writing-driven innovation, nothing really follows from the fact that an early written attestation of 'something new' happens to be included in Frown or FLOB. What Lass (1980, p. 95) writes following Bloomfield (1933, p. 347ff) of the situation in general:

The irreducible fact seems to be that we can never observe the 'exact moment' when a change begins (except by accident - and even then we would still have no way of knowing what we were actually observing).

is a fortiori true of the present approach, which relies on written data exclusively.

So the central focus is not on the event of creation but on the spread of an innovative element, which is chiefly registered as a shift in the proportion of variant forms over time.

It goes without saying that written corpora are useless for the study of sound change; corpora the size of FLOB and Frown are also too small to systematically investigate neologisms and most word-formation processes. Thus, grammatical change, especially in the domain of high-frequency phenomena, will be the most promising area to look for results.

\section{Previous research on grammatical change in present-day English}

Received wisdom on the subject is largely laid down in three monographs two of which (Barber, 1964 and Potter, 1969) present the results of informed personal observation, whereas Bauer (1994) is the first to try a corpus-based approach on a very small scale. In view of the fact that texts from one genre (Times editorials written between 1900 and 1985) making up a total of no more than 200,000 words are meant to document 18 successive stages of the language between 1900 and 1985, the results remain inconclusive.

The following grammatical changes are suspected to be going on in standard English at present:

a) analogical regularisation of irregular plurals of nouns, past-tense and past-participle forms of verbs;

b) blurring of case distinctions in pronouns (e.g. he/him) and loss of whom;

c) increase in the frequency of the s-genitive with inanimate nouns;

\footnotetext{
${ }^{1}$ Frown for "Freiburg version of the Brown corpus"; FLOB for "Freiburg version of the LOB corpus". The reader is asked to forgive the puns.
} 
d) decrease in the frequency of inflectional comparison with disyllabic and to some extent even monosyllabic adjectives;

e) increase in the frequency of the progressive and the going-to-future; new uses of the progressive with 'stative' verb phrases;

f) past-tense forms encroaching on the past perfect and the present perfect;

g) a number of developments in the modal and auxiliary verb systems (e.g. disappearance of shall in the future tense, marginalisation of ought to, regularisation of have, need, dare and used to in questions and negations, grammaticalisation of wanna and gotta, may replacing might in certain uses);

h) increase in the number and frequency of use of phrasal verbs;

i) a number of partly conflicting developments in the field of noun-verb concord (growing acceptance of 'singular' they and reduced tolerance for plural verbs with collective nouns - cf. the type the government are...);

j) revival of the subjunctive in formal styles.

In addition to these trends there is a number of lexico-grammatical developments which usually affect individual lexical items only and are normally due to changes in meaning which will of course affect the syntactic frames they become available for (e.g. that's a nonsense, commented on in Greenbaum, 1986, p. 6-7), reanalysis (due to), conversion (like used as a conjunction) or gradual grammaticalisation (quasiprepositional uses of the participle following, cf. Olofsson, 1990). Such phenomena tend to go unnoticed unless they incur the wrath of prescriptivists, in which case their significance is blown out of all proportion, as in the holy war on hopefully (cf. Greenbaum, 1988, p. 11).

I will continue now with a brief section on some results obtained so far with 'hard' statistical approaches (Section 3). However, the most fruitful area of research seems to lie where relatively modest statistics is used to test specific hypotheses advanced in the theoretical literature, for example in publications on grammaticalisation theory. The benefits to be derived from this co-operation between corpuslinguists and more theoretically minded colleagues are obvious. Corpus-linguists sometimes go about their business with a degree of naiveness, happily adding a further set of statistics to existing counts, and not worrying too much about any broader significance of such findings. Grammaticalisation theory, on the other hand, works with a limited number of time-honoured study examples (such as the grammaticalisation of go and related verbs as future markers in many languages), but has a serious evidence problem once attention shifts to the study of more recent phenomena. It seems that to bring the two together would be a good idea because they support each other in precisely those areas where they are weakest. This is an idea which will be explored and illustrated in Section 4 below.

Section 5 will argue that some of the most drastic changes to be observed in the use of grammatical forms are not directly due to grammatical innovation. Rather, they reflect a colloquialisation of written English, that is a change in stylistic conventions which is due to a current of informalisation and (pseudo)democratisation affecting advanced industrial societies (cf. Hobsbawm, 1994; Featherstone, 1991; Elias, 1989).

\section{Changing English grammar: some statistically significant developments}

Mair \& Hundt (1995) have shown that there are practically no ${ }^{2}$ statistically significant differences in the use of the progressive in the press sections of Brown and LOB. In other words, the corpora do not show evidence for a regional contrast in the use of the progressive between American and British English. There are, however, 'very significant' and 'significant' contrasts between LOB and FLOB, and between Brown and Frown. This proves that the use of the progressive has changed over the past thirty years. The most interesting figures are the following:

\footnotetext{
${ }^{2}$ The one exception is the future progressive, which is more frequent in the British material at significance level "c" (= "significant", as against "b - very significant" and "a - highly significant", cf. Mair \& Hundt, 1995, p. 120-121).
} 


\begin{tabular}{lllll} 
& Brown $A-C$ & Frown $A-C$ & LOB A-C & FLOB A-C \\
\hline present progressives & 349 & 408 & 340 & 408 \\
total progressives & 593 & 663 & 606 & 715 \\
\hline
\end{tabular}

Table 1: Progressive forms in four corpora.

The contrasts between Brown and Frown are 'significant', those between LOB and FLOB are 'very significant'. In a detailed qualitative analysis of the material no immediate grammatical causes were identified for the increase that was observed. Alleged new uses such as the progressive with stative verbs or structures of the type 'expletive it + is being' (e.g. it was being the afternoon of a lifetime) were either already present in the old material or not even attested in the new. In any event, such uses are so rare that they would not have influenced the statistics, at all. Thus, the only explanation for the increase is that the progressive is used more often today in those cases in which there has been a choice between simple and progressive forms for a long time. As in such cases the progressive is usually considered the informal stylistic option, the issue will be taken up again in Section 5.

The same study also showed that the going-to-future had become more frequent (Mair \& Hundt, 1995, p. 114):

\begin{tabular}{lllll}
\hline & Brown $A-C$ & Frown $A-C$ & LOB A-C & FLOB $A-C$ \\
\hline going-to-futures in direct speech & 7 & 51 & 9 & 19 \\
going-to-futures (total) & $\mathbf{3 0}$ & $\mathbf{6 7}$ & $\mathbf{3 0}$ & $\mathbf{4 6}$ \\
\hline
\end{tabular}

Table 2: Going-to-futures in four corpora.

The greater frequency of the form in the new material is not due to the presence of new uses. Again, the most likely explanation of the increase is that an existing informal stylistic option is used more often in writing than was the case thirty years ago.

In two of the most laborious studies undertaken on the material so far, Siemund (1993) and RaabFischer (1995) have established that the frequency of the inflectional genitive has increased in roughly the same measure that genitival of -phrases have become rarer. From their findings, I have compiled the following table, giving the ' $s / o f$-ratios for seven noun classes:

\begin{tabular}{lcc}
\hline & $L O B A-C$ & $F L O B A-C$ \\
\hline personal names & $443: 178$ & $692: 170$ \\
personal nouns & $259: 483$ & $245: 360$ \\
collective nouns & $175: 528$ & $311: 381$ \\
higher animals & $5: 8$ & $9: 9$ \\
geographical/locative nouns & $159: 478$ & $286: 331$ \\
temporal nouns & $80: 149$ & $120: 144$ \\
other nouns & $38: 2059$ & $79: 1984$ \\
all nouns & $\mathbf{1 1 5 9 : 3 8 8 3}$ & $\mathbf{1 7 4 2 : 3 3 7 9}$ \\
\hline
\end{tabular}

Table 3: $S$-genitives vs. of -genitives in seven noun classes.

Again, we are faced with the by now familiar situation: an alleged 'new' use, the $s$-genitive with 'other' nouns, has increased considerably, but the greater part of the fluctuation is accounted for by changing preferences in areas where there has been variation for a long time already. Stylistic factors seem to be involved, but they are less clearly related to the spoken/written dimension than was the case with the progressive and the going-to-future.

A final example, in which the influence of spoken English on writing is obvious immediately, is the 
growing tolerance of contractions in writing. From the many results in Krug (1994), the following figures on it's are particularly striking:

\begin{tabular}{llcll}
\hline & $L O B A-C$ & $F L O B A-C$ & Brown $A-C$ & Frown $A-C$ \\
\hline in quotations & 15 & 44 & 13 & 90 \\
in 'Headlines' & 1 & 8 & 4 & 11 \\
in normal text & 7 & 48 & 30 & 112 \\
total & $\mathbf{2 3 ( 4 7 9 )}$ & $\mathbf{1 0 0 ( 3 4 5 )}$ & $\mathbf{4 7}(\mathbf{2 6 7})$ & $\mathbf{2 1 3 ( 1 6 0 )}$ \\
\hline
\end{tabular}

Table 4: Use of $i t$ 's in four corpora.

The figures in brackets give the numbers for uncontracted forms. The results show that the contraction rates of spoken English have not been reached yet, but that a giant stride towards this has been taken in the past thirty years, particularly in written American English, where the contracted form it's is already the statistical norm.

\section{Changing English grammar: incipient grammaticalisation}

In contrast to the high-frequency phenomena discussed in the preceding section, the figures reported here are suggestive but not conclusive. However, I think it is well to remind ourselves that the relationship between statistical and linguistic significance is a complex one: there are statistically significant patterns in corpora which cannot be interpreted linguistically, and some linguistically significant facts from corpora are not statistical.

Grammaticalisation theory, that is the study of how grammatical morphemes are produced from the lexicon, is one of the fastest growing areas of modern linguistic theory (see Mair, 1994 for references). What made me think of bringing corpus-linguistics and grammaticalisation theory together were frequent assertions on the part of grammaticalisation theorists that their method-so successful in the study of remote linguistic history - failed in the analysis of ongoing changes. Compare, for example, the following statement:

Die früheste Phase der Grammatikalisierung-also die Entstehung von Formeln und einfachen 'pattern'-aktuell zu verfolgen, ist phänomenologisch unmöglich. Ungeheure Massen an Diskursen mit einem potentiell grammatikalisierenden Kandidaten müßten aufgezeichnet und, vor allem ausgewertet, werden, doch nach welchen Kriterien? Und welche sind die Kandidaten? (Compes et al., 1993, p. 20)

[To document the earliest stage of grammaticalisation, that is the emergence of formulæ and simple patterns, is phenomenologically impossible. Huge masses of discourse containing a potential candidate for grammaticalisation would have to be sifted and-what is more-evaluated. But according to what criteria? And which are the candidates?]

The study of grammatical change on the basis of data on synchronic (or, at best, brachychronic) variation in the contemporary stage of a language is subject to a serious problem of verification. Given presently available methodological means, it is next to impossible to know which of the changes that speech habits currently exhibit are synchronic manifestations of ongoing genuine language change, and which of them are but ephemeral fashions. (Lehmann, 1991, p. 532)

I find such scepticism unwarranted in the age of corpus-linguistics. Do we not have the masses of discourse that Compes et al. (1993) call for readily available in the form of an ever increasing number of newspapers on CD-ROM piling up annually? And aren't the LOB/FLOB and Brown/Frown corpora a 
'presently available methodological means' for disentagling synchronic variation and genuine change in 'brachychronic' dimensions? ? $^{3}$

Mair (1994) has identified some uses of see which could with some justification be regarded as candidates for early grammaticalisation. In Mair (1995) it is argued that the use of the verb help has changed rapidly in British English over the past thirty years. Not only has the bare infinitive now become the norm also in Britain, but in both British and American English the overall frequency of help + infinitive has increased steeply. Here is the updated version of the table in Mair (1995, p. 264):

\begin{tabular}{lclcl}
\hline & LOB A-C & FLOB A-C & Brown A-C & Frown $A-C$ \\
\hline 1. help + bare inf. & 4 & 21 & 9 & 36 \\
2. help + object + bare inf. & 1 & 8 & 10 & 21 \\
3. help + to-inf. & 14 & 6 & 5 & 7 \\
4. help + object + to-inf. & 3 & 7 & 4 & 2 \\
$\quad$ bare inf.: to-inf. & 17 & $29: 13$ & $19: 9$ & $57: 9$ \\
total & $\mathbf{2 2}$ & $\mathbf{4 2}$ & $\mathbf{2 8}$ & $\mathbf{6 6}$ \\
\hline
\end{tabular}

Table 5: Use of help + infinitive in four corpora.

With the new figures from Frown the original hypothesis can be defended even more strongly: certain semi-idiomatic uses of help, in which the verb is used with prepositional force (e.g. more money to help pay the bill, which is roughly equivalent to more money for paying the bill) are grammaticalising, with the presumable end-point of the development being the addition of another complex deverbal preposition to the inventory of existing ones. Provisional spot checks on the not yet completed remaining portions of the corpora show that the development is not peculiar to the language of the press - a possibility which was mentioned in a cautionary remark in the original study (Mair, 1995, p. 270).

It is expected that the combination of statistical and qualitative textlinguistic methods in the study of this and similar phenomena will be one of the most productive uses the completed corpora will eventually be put to.

\section{The 'colloquialisation' of the norms of written English}

It seems that a project originally designed to document ongoing grammatical changes in present-day English has in fact produced a record of a sociolinguistic or discourse-historical phenomenon - the 'colloquialisation' of the norms of written English which has taken place over the past thirty years or so. The increasing frequency of the progressive and the going-to future, writers' growing willingness to use contracted forms, and to some extent also the shifts noted in the choice between inflectional and periphrastic genitives are not due to the fact that the grammar of the language itself has changed. Rather, these developments show that informal options which have been available for a long time are chosen more frequently today than would have been the case thirty years ago. Pending the completion of FLOB and Frown, this can be demonstrated for the English of newspapers only, but it seems plausible to generalise the observation to written English as a whole.

The colloquialisation of the norms of written usage reflected in our parallel corpora is the linguistic correlate of a general societal trend, namely an informalisation of manners and codes of conduct that several historians and sociologists have considered as typical of the advanced industrialised societies that arose in the West after World War II (see Hobsbawm, 1994, p. 331 and passim, Elias, 1989, p. 31158, on 'Zivilisation und Informalisierung', Featherstone, 1991, p. 45, 59-60). The late nineteen-sixties and early seventies, with their student rebellions, are regarded as the watershed in the transition from societies marked by formal and explicitly hierarchical institutional structures and rigid codes of decorum

\footnotetext{
${ }^{3}$ It is true that for the study of the very early stages of grammaticalisation similar quantities of spoken material would be necessary, and this is indeed a limitation.
} 
to societies which were more democratic-the optimistic interpretation-or veiled existing hierarchical structures through the promotion of an egalitarian and informal public atmosphere (thus the pessimist's interpretation). It so happens that LOB and Brown were sampled shortly before the '1968' cultural revolt, and our corpora about two decades later, so that its linguistic repercussions are fortuitously captured in our material.

Sociologists and historians who are interested in the process of informalisation concern themselves mostly with the socio-psychological aspects of the phenomenon. Elias (1989), for example, has argued that-contrary to what one would think-the more easygoing manners of today should not be interpreted as a weakening of emotional controls in the individual but as a strengthening, because only the highly controlled individual can cope with the many choices available in a social climate as informal and unstructured as the present one. Rigidly enforced external norms compensate for individual weaknesses, but a strong sense of self is required to survive in an atmosphere of public anomie. But as the present paper is certainly not the place to explore this philosophical argument any further, let us turn to the possible consequences the move toward informalisation may have had for recent language history. Elias himself notes that changes in the communicative conventions of a society are clear clues to what may be going on under the surface. His Studien über die Deutschen has insightful comments on different modes of address among university students and students and staff in the Weimar Republic and the early years of the Federal Republic on the one hand, and present-day Germany on the other (p. 329-360). Similarly, Hobsbawm (1994) characterises the nineteen-sixties as marked by a demotic turn in the tastes of the middle- and upper-class young in the Western world' (p. 331), a formulation which easily accommodates the linguistic developments that emerge from a comparison of our parallel corpora. Hobsbawm also insists that this demotic turn is a double-edged phenomenon. On the one hand, it may be emancipatory - a sign of genuine interest in and respect for the way of life of the lower classes. On the other hand, it could be exploitative - using elements borrowed from the culture of the underdog out of context, in order to shock the elite without eroding its position of power.

In interpreting the findings from the corpora, is there anything more to say than that the development of stylistic conventions parallels the development of society as a whole - a point which should be fairly uncontentious? Can we perhaps more systematically describe the way in which the two trends interact? Here the work of Norman Fairclough and the school of Critical Discourse Analysis it has inspired is helpful even for those who do not share the movement's left-wing political activism.

Fairclough (1992) investigates 'discourse and social change in contemporary society' (thus the title of a chapter in his p. 200-224) ${ }^{4}$. He identifies three major recent shifts in the field of communicative norms, namely the democratisation, the commodification, and the technologisation of discourse. The two lastnamed tendencies need not concern us here, but 'informality', a narrowing of the gap between the norms of speech and writing, is seen as a constituent part of the democratisation of discourse. Fairclough sees it as proceeding alongside changes in:

relations between languages and social dialects, access to prestigious discourse types, elimination of overt power markers in institutional discourse types with unequal power relations [...] and changes in gender-related practices in language. (Fairclough, 1992, p. 201)

In a somewhat extravagant metaphor, conversational discourse is said to 'colonise' the media and many other domains originally considered the preserve of formal/written styles:

One dimension of this manifestation of informality is a shift in the relationship between spoken and written discourse. We had examples of this from newspapers [...] one finds the shift towards conversation not only throughout the printed media and advertising, but also in new designs for official forms, such as claim forms for social welfare payments [...]. The shifts of speech

\footnotetext{
${ }^{4}$ Although he is based at Lancaster, one of the hotbeds of corpus-linguistics, it is interesting to note that it does not occur to him to do so on the basis of corpora, but this is beside the point here.
} 
towards writing may have had their heyday; contemporary cultural values place a high valuation on informality, and the predominant shift is towards speech-like forms in writing. (Fairclough, 1992, p. 204)

Being the ever-vigilant social activist, Fairclough concludes with a warning: 'there is a question about the extent to which informality is simulated for strategic reasons; I return to this below' (p. 205).

One interesting issue which is certainly open to systematic investigation by corpus-linguists is the relationship between colloquial writing and real speech. It is true that more and more spoken features make it into written English, but this is only part of the story. In addition, there is a range of linguistic features that are rare or absent in speech but are also used to lend an informal flavour to a written text, for example noun-phrase name appositions of the type Labour Leader Tony Blair (for Tony Blair, the Labour Leader) or aging revolutionary leader Fidel Castro (for Fidel Castro, the aging revolutionary leader) investigated in Jucker (1992). The colloquialisation of the norms of written English is thus a phenomenon which comprises two distinct but interlocking components: genuine informality, that is the more or less unconscious carrying over of spoken/conversational features into writing, and anti-formality, which could be defined as the conscious deployment of selected stylistic markers in order to reduce the degree of formality of a text ${ }^{5}$. The analysis of colloquialisation is certainly not made easier by the fact that quite often one and the same linguistic marker may be a signal either of informality or of anti-formality - depending on whether it is used unconsciously or as a consciously deployed rhetorical device.

In charting the spread of spoken/conversational features through writing, it would be interesting to see whether it proceeds across the board, or whether there are privileged points of entry, for example quotations or passages at the beginning or the end of articles in which it is particularly important to establish direct rapport with one's readership. In his study of contractions Krug has pointed out the frequent use of what he calls 'farewell contractions,' showing that the latter is probably the case. A second look at the material also makes it obvious that the steep rise in the use of the going-to-future is almost entirely due to its use in direct quotations: a full 51 of the 67 instances in Frown occur in passages of direct speech, and the lesser increase in FLOB can be accounted for in the same way.

\section{Conclusion}

The paper has presented some results obtained so far in the comparison of the $1961 \mathrm{LOB}$ and Brown and the 1991/1992 FLOB and Frown corpora. Very few genuine instances of grammatical change were noted. Most changes observed could be interpreted as a result of the colloquialisation of the norms of written English which has taken place over the past thirty years. This colloquialisation is the linguistic correlate of a general social trend towards greater informality. Within corpus linguistics, the present study can be seen as a continuation of the very few previous attempts to use ICAME corpora as resources for cultural studies (cf., e.g. Hofland \& Johansson, 1982, Leech \& Fallon, $1992^{6}$, and most recently Stubbs, 1996); in a broader linguistic context, I hope that it has pointed out one way in which corpus linguistics could contribute to an important new interdisciplinary field of study, the historical evolution of discourse conventions.

\section{References}

Allsopp, R. (1996). Dictionary of Caribbean English usage, Oxford University Press, Oxford.

\footnotetext{
${ }^{5}$ The distinction between informal and anti-formal styles follows ideas laid own in Allsopp (1996).

${ }^{6}$ This study reports on the results of a comparative lexical-content analysis of Brown and LOB, the daring summary of which deserves quotation: "Wrapping up the whole analysis [...] in one wild generalization, we may propose a picture of US culture in 1961 - masculine to the point of machismo, militaristic, dynamic and actuated by high ideals, driven by technology, activity and enterprise - contrasting with one of British culture as more given to temporizing and talking, to benefitting from wealth rather than creating it, and to family and emotional life, less actuated by matters of substance than by considerations of outward status." (p. 44-45).
} 
Barber, Ch. (1964). Linguistic change in present-day English, Oliver and Boyd, London and Edinburgh.

Bauer, L. (1994). Watching English change: An introduction to the study of linguistic change in standard Englishes in the 20th century, Longman, London.

Biber, D., Finegan, E. \& Atkinson, D. (1994). ARCHER and its challenges: Compiling and exploring a representative corpus of historical English registers, in U. Fries, G. Tottie \& P. Schneider (eds), Creating and using English language corpora: Papers from the Fourteenth International Conference on English Language Research on Computerized Corpora, Zürich, 1993, Rodopi, Amsterdam, p. 1-14.

Bloomfield, L. (1933). Language, Holt, Rinehart and Winston, New York.

Compes, I., Kutscher, S. \& Rudorf, C. (1993). Pfade der Grammatikalisierung: Ein systematisierter Überblick, Arbeitspapier 17, Institut für Sprachwissenschaft der Universität, Köln.

Elias, N. (1989). Studien über die Deutschen: Machtkämpfe und Habitusentwicklung im 19. und 20. Jabrbundert, edited by M. Schröter, Suhrkamp, Frankfurt.

Fairclough, N. (1992). Discourse and social change, Polity Press, Cambridge.

Featherstone, M. (1991). Consumer culture and postmodernism, Sage, London.

Gloderer, G. (1993). Morphological regularisation of irregular verbs: A comparison of British and American English, unpublished M.A. Thesis, Freiburg.

Graf, D. (1996). Relative clauses in their discourse context: A corpus-based study, unpublished M.A. Thesis, Freiburg.

Greenbaum, S. (1986). The Grammar of Contemporary English and The Comprehensive Grammar of the English Language, in G. Leitner (ed.), The English Reference Grammar, Niemeyer, Tübingen, p. 6-14.

Greenbaum, S. (1988). Good English and the grammarian, Longman, London.

Hobsbawm, E. (1994). Age of extremes: The short twentieth century 1914-1991, Michael Joseph, London.

Hofland, K. \& Johansson, S. (1982). Word frequencies in British and American English, Norwegian Computing Center for the Humanities, Bergen.

Holmes, J. (1994). Inferring language change from computer corpora: Some methodological problems, in "ICAME", 18, p. 27-40.

Hundt, M. (1996). New Zealand English and its relation to British and American English: A corpus-based study in morphosyntactic variation, Ph.D. Thesis, Freiburg.

Jespersen, O. (1909-1949). A modern English grammar on historical principles, 7 vols., Munksgaard, Copenhagen.

Jucker, A. (1992). Social stylistics: Syntactic variation in British newspapers, Mouton de Gruyter, Berlin and New York, CrossRef.

Krug, M. (1994). Contractions in spoken and written English: A corpus-based study of short-term developments since 1960, unpublished M.A. Thesis, Exeter.

Lass, R. (1980). On explaining language change, Cambridge University Press, Cambridge.

Leech, G. \& Fallon, R. (1992). Computer corpora: What do they tell us about culture?, in “ICAME", 16, p. 29-50.

Lehmann, C. (1991). Grammaticalization and related changes in contemporary German, in E. Closs Traugott \& B. Heine (eds), Approaches to grammaticalisation, vol. II, Benjamins, Amsterdam, p. 493-535, CrossRef.

Lovejoy, J. (1995). Prepositions in British and American English: A computer-aided corpus study, in "AAA", 20, p. 55-74.

Mair, C. (1994). Is see becoming a conjunction? The study of grammaticalisation as a meeting ground for corpus linguistics and grammatical theory, in U. Fries, G. Tottie \& P. Schneider (eds), Creating and using English language corpora: Papers from the Fourteenth International Conference on English Language Research on Computerized Corpora, Zürich, 1993, Rodopi, Amsterdam, p. 127-137.

Mair, C. (1995). Changing patterns of complementation, and concomitant grammaticalisation, of the verb help in present-day British English, in B. Aarts \& Ch. F. Meyer (eds), The verb in contemporary English: theory and description, Oxford University Press, Oxford, p. 258-272.

Mair, C. \& Hundt, M. (1995). Why is the progressive becoming more frequent in English? - A corpus-based investigation of language change in progress, in "Zeitschrift für Anglistik und Amerikanistik", 43, p. 111-122.

Olofsson, A. (1990). A participle caught in the act: On the prepositional use offollowing, in “Studia Neophilologica", 62, p. 23-35, 129-149, CrossRef.

Potter, S. (1969), $2^{\text {nd }}$ ed. 1975. Changing English, André Deutsch, London.

Raab-Fischer, R. (1995). Löst der Genitiv die Of-Phrase ab? Eine korpusgestützte Studie zum Sprachwandel im heutigen English, in "Zeitschrift für Anglistik und Amerikanistik", 43, p. 123-132.

Sand, A. \& Siemund, R. (1992). LOB - 30 years on ..., in "ICAME", 16, p. 119-122.

Sand, A. (1996). Linguistic variation in Jamaica: A corpus-based analysis of radio and newspaper language, Ph.D. Thesis, Freiburg.

Siemund, R. (1993). Aspects of language change in progress: A corpus-based study of British newspaper English in 1961 and 1991, unpublished M.A. Thesis, Freiburg.

Siemund, R. (1995). For who the bell tolls: Why corpus linguistics should carry the bell in the study of language change in presentday English, in "AAA", 20, p. 351-377.

Skandera, P. (1995). Computergestützte Korpuslinguistik und Sprachwandelforschung: Grammatische Neuerungen in der amerikanischen Pressesprache seit 1961, unpublished M.A. Thesis, Freiburg.

Stubbs, M. (1996). Text and corpus analysis, Blackwell, Oxford. 